\title{
PECULIARITIES OF DIAGNOSIS IN THE PHYLLODES TUMOR
}

\author{
O. Andronic ${ }^{1}$, D. Ion ${ }^{1,2}$, Izabela Marin ${ }^{1}$, Georgiana Radu ${ }^{1}$, D.N. Păduraru ${ }^{1,2}$ \\ ${ }^{1}$ The University of Medicine and Pharmacy "Carol Davila", Bucharest, Romania \\ ${ }^{2}$ General Surgery and Emergency Clinic III - The University Emergency Hospital of Bucharest, Romania
}

Corresponding author: Dan Nicolae Păduraru

Phone no. 0040744756443

E-mail: dan.paduraru.nicolae@gmail.com

\begin{abstract}
Phyllodes tumor (PT) is an uncommon and distinct category of breast cancer, being a particular form of intracanalicular fibroadenoma. A definitive diagnosis is difficult to make just based on imaging investigations and fine needle biopsy; also PTs are frequently misinterpreted as breast fibroadenomas. In the case of of a 26-year old woman with a suspected PT (based on clinical investigation) which was first diagnosed as a fibroadenoma using ultrasonography and preoperative biopsy, further investigation was needed. A limited resection was performed and the postoperative histopathology confirmed the diagnosis as PT.
\end{abstract}

Keywords: Phyllodes tumor, fibroadenoma, breast cancer

\section{Introduction}

Breast oncologic pathology represents a real challenge in terms of correct diagnosis in its early stages, in order to establish as quick as possible an optimal therapeutic management. Breast cancer represents the most frequent incriminated oncologic pathology which affects women $(29 \%$ of all the cancer diagnosed cases in women and $13 \%$ of all diagnosed cancers [1]).

Phyllodes tumors (PT) represent a special category of breast cancer, it being a particular form of intracanalicular fibroadenoma with a bitissular structure: epithelial and connective [2]. Because of the foil-like aspect it is also called Phyllodes tumor, the name originating from Greek, "phyllo"=leaf. A microscopic evaluation divides PT into three categories: benignant, borderline and malignant [3], the last of the three having a $15-30 \%$ chance of occurence[4]. In their least aggressive form, PTs have a behavior similar to fibroadenomas, but present a high risk of relapse after a resection with insufficiently wide borders. On the other hand at the other end of the spectrum we have the malignant PT showing sarcomatous degeneration [5].

PT incidences are low, under 0.25 in 100000 cases, and represent under $2 \%$ of all breast cancers in women [6-9].

Risk factors incriminated in the incurrence of PT are similar to all breast cancer masses, the most important being the feminine sex[9]. The maximum occurrence appears to be at around the age of 45 [10], the masses arising either on a healthy breast or on a pre-existent mass having different characteristics [11,12].

Clinical exam highlights in most cases an unique tumor[13], oval-shaped, well delimited, having various dimensions that can reach $50 \mathrm{~cm}$ $[14,15]$. Palpating it, the tumor can be usually described as a multilobed mass, with areas of variable consistency, non-adherent to the surrounding plans [16]. Because of the stretched 
skin overlying and the irrigation disorders, voluminous tumors may develop a shiny, tense tegument, with a pale or hyperemic color and venous dilatation expansion [17]. The most frequent location of $\mathrm{PT}$ is in the superior-extern dial[18]. Although the axillary adenopathies can be probed in more than $20 \%$ of the cases, during the clinical examination, their metastatic implication is usually rare [19].

No investigation technique based on imaging examination can be used to establish a certainty diagnosis, the differences between PT and fibroadenoma being most of the times too hard to see. Although, we must not forget of the ultrasonography and the mamography which have an important role in the orientation of the preoperatory diagnosis in order to have a correct management of the case [20]. The typical mamographic aspect of a PT is a cancerous mass with multiple lobes and well delimited.

Thin needle aspiration provide a high rate of false negative results and has a low accuracy for the diagnosis of PT [21]. Also, macrobiopsy is as inefficient, it having a $30 \%$ false positive rate [21].

For breast fibroadenoma it is preferable to use a conservatory management, with clinical surveillance. On the other hand, in case of PT, taking into account the malignancy risk along with the recurrence risk, a segmentary or total resection must be performed, with or without limfadenectomy according to the tumor's staging. Due to these reasons it is very important to differentiate between PT and fibroadenoma or any other kind of tumors with malignant character or potential ones [23-25].

\section{Case report}

To further study the subject, let us take into account the case of A.M., a 26 year old patient, who presented herself at no. III Clinic of Surgery of Emergency Teaching Hospital Bucharest, due to the occurrence of a cancerous mass in the left breast which had been evolving for almost 6 months(Figure 1). Her personal history did not reveal any other significant elements.

The clinical exam highlighted a left breast tumor about $8 \mathrm{~cm}$ diameter, movable on the surrounding plans, painless, well defined, with an overlying tegument having significant venous expansions(Figure 2 and 3). The ganglionic exam did not reveal palpable lymph nodes.

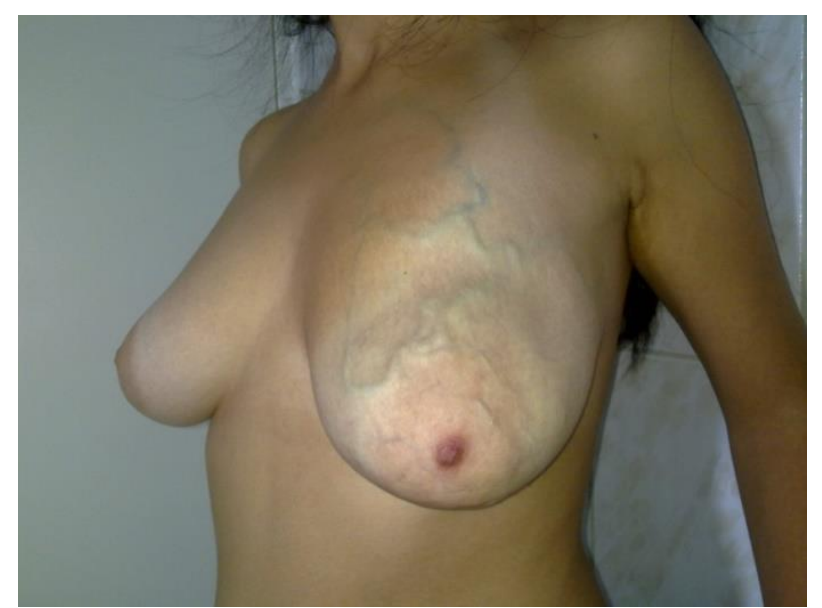

Figure 1 - Clinical examination - left breast inspection showing subcutaneous venous expansions

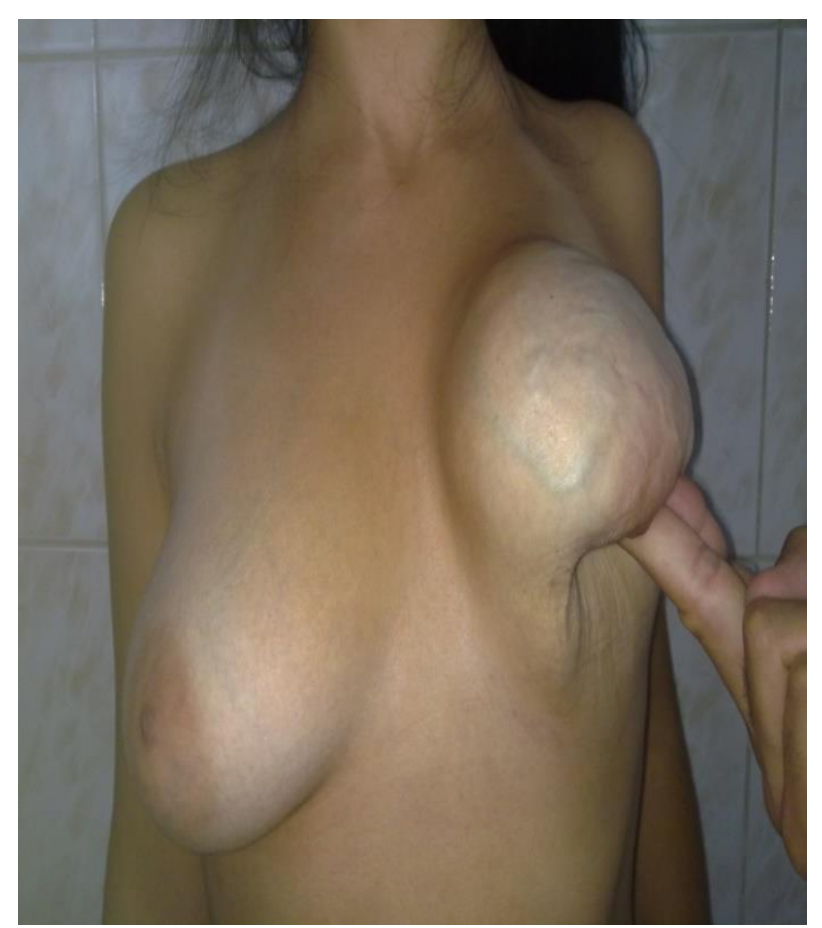

Figure 2 - Clinical examination - delimitation of tumor formation

Breast echographic exam suggested benign characteristics, therefore the ultrasonographic diagnosis was hyperecogenous tumor formation with perilesional vascularity, approximate dimensions 80/65/40 $\mathrm{mm}$, with benign characters - fibroadenoma.

Because the clinical examination indicated formations oriented towards a Phillodes tumor, fine needle puncture biopsy had been ordered as a first step in pursuing the case. The 
histopathological result of the biopsy fragment was breast fibroadenoma.

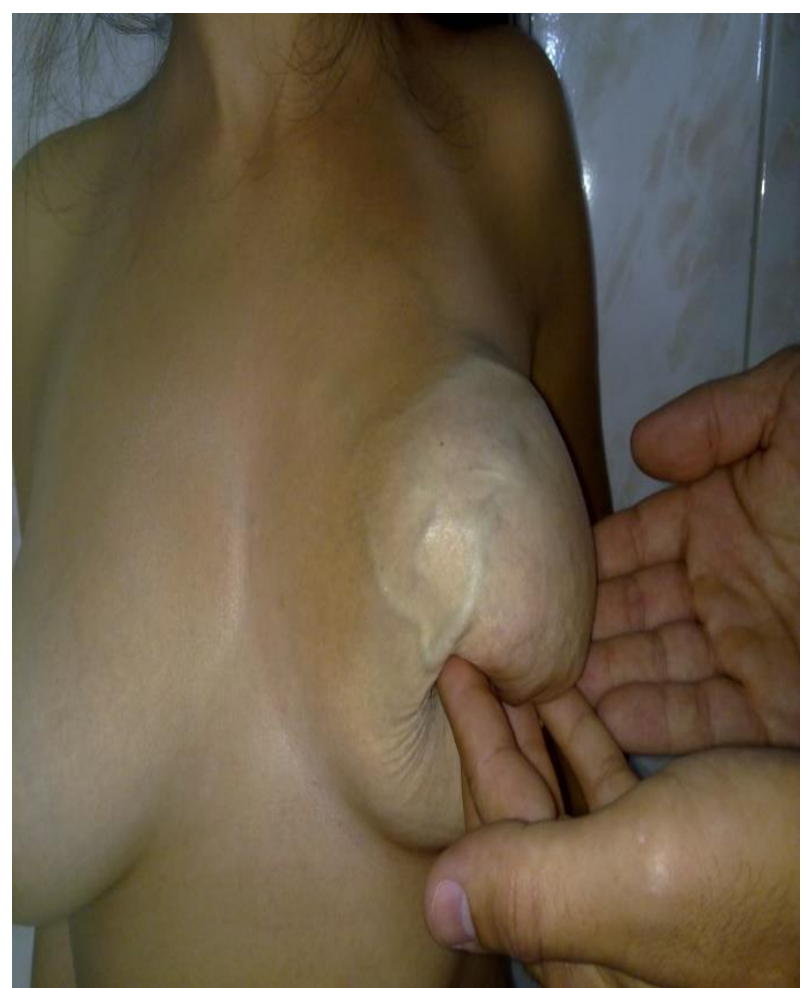

Figure 3 - Clinical Examination - observation of the vascular expansions and delimiting of the inferior edge of the tumor

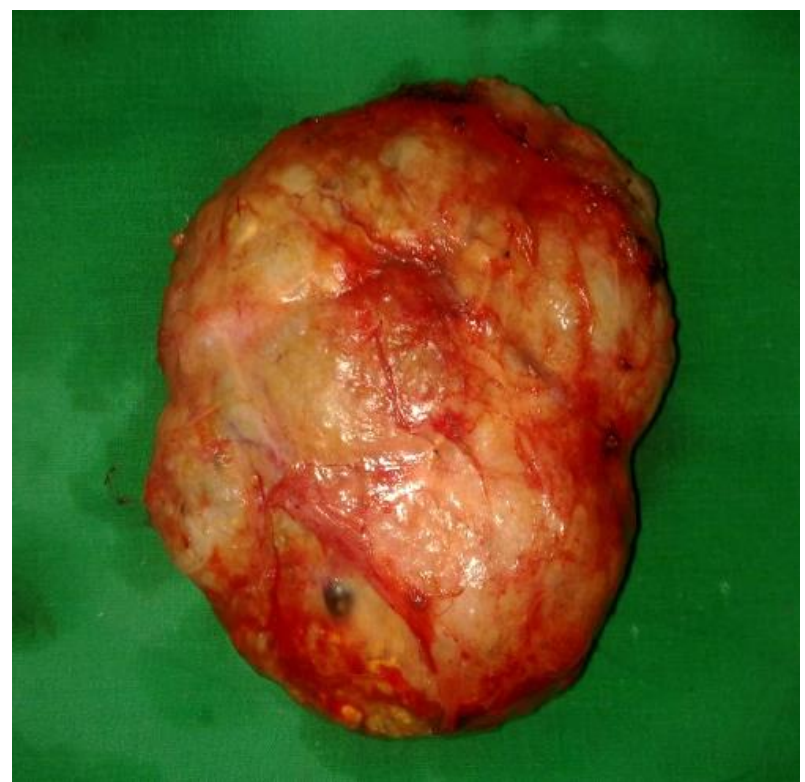

Figure 4 - The macroscopic aspect of the resection piece

Following the results of ultrasonography and biospsy, given the large size of the tumor, it was decided that a scheduled surgery for a limited mammary resection is the correct therapeutic procedure. Further along, a intraoperative tumor formation was found pseudo-encapsulated, noninvasive in the adjacent tissue, with a diameter of around $6 \mathrm{~cm}$. The resection of the tumor formation was ordered and was well accomplished, with oncological safety edges of $1 \mathrm{~cm}$, after which the piece was sent to anatomopathological examination(Figure 3 and 4). Histopathological examination confirmed the initial suspicion of Phyllodes tumor of benign nature.

The postoperative evolution was favorable, the patient was discharged the 3 rd postoperative day, having been legally considered surgically cured.

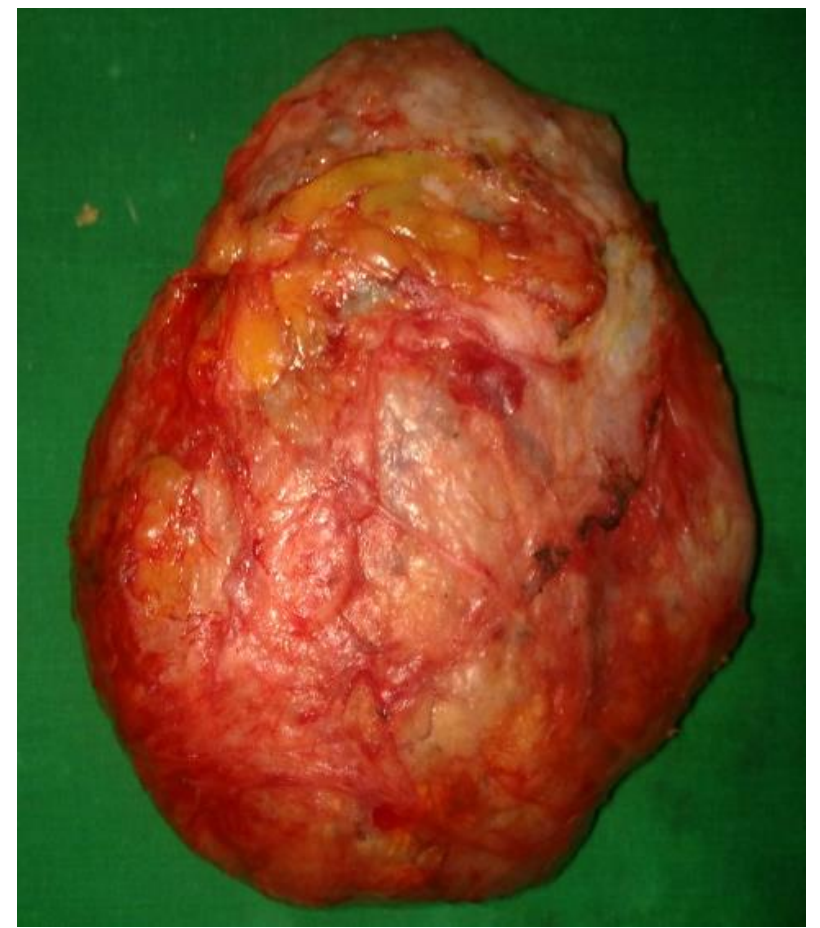

Figure 5 - The macroscopic aspect of the resection piece

\section{Discussions}

Clinical studies have revealed the difficulty of the differencial diagnosis between PT and breast fibroadenoma[26-28]. In this case, the clinical examination suggested a PT diagnosis, which was later infirmed by the ultrasonograhy and thin needle biopsy. Initial suspicions were confirmed postoperatory, the final diagnosis being PT. Due to the high rate of false negative results of the puncture, for positive diagnosis of PT, excisional biopsy of any breast tumor is required every time it becomes symptomatic or its volume increases rapidly.

Because of these difficulties, a thorough clinical examination appears to be of great 
importance, mostly because it may direct the management to surgical or conservative approach. Phyllodes sarcoma is a anatomopathological form whith an extremely aggressive evolution[29,30], and therefore it is essential to take into consideration surgical management even if the PT is benign because of its real risk of malignancy [4].

Although the maximum incidence of PT is between 35-55 years[9], this diagnosis should not lose sight of young patients that present a high degree of suspicion after a clinical examination.

PT surgical resection should be performed with wider margin of safety of $1 \mathrm{~cm}$; this limit being larger than the one for breast carcinoma. On the other hand, a misinterpretation of these PTs as breast fibroadenomas, frequently leads to excision with unfit margins of safety, and a high rate of local recurrence. Evidence shows current rate of local recurrence after local resection with negative margins, $24 \%$ for borderline PT and 20\% for malingant PT. Adjuvant radiation therapy added to the resection with negative margins improves local control of the disease [31]. Given the low rate of metastasis in axillary lymph nodes, even for malignant TP, current studies indicate that axillary lymphadenectomy is unnecessary.

\section{Conclusions}

Phyllodes tumor, although a rare type of breast neoplasia remains difficult to diagnose by current means of imaging and even biopsy. Clinical examination should be the start procedure, guiding the clinician towards a correct diagnosis, which can then be later confirmed pre or post operatively. Excluding this type of tumor from the differential diagnosis is essential in order to ensure a favorable long term evolution of the patient.

\section{References}

[1]Ferlay J, Soerjomataram I, Ervik M, et al. GLOBOCAN 2012 v1.0, Cancer Incidence and Mortality Worldwide: IARC CancerBase No. 11 [Internet]. Lyon, France: International Agency for Research on Cancer; 2013.
[2]Moinfar F. Biphasic tumors. In: Moinfar F, editor. Essentials of Diagnostic Breast Pathology: A Practical Approach. New York, NY: Springer; 2007. pp. 320-50.

[3] Mituś JW, Blecharz P, Reinfuss M, Kulpa JK, Skotnicki P, Wysocki WM. Changes in the clinical characteristics, treatment options, and therapy outcomes in patients with phyllodes tumor of the breast during 55 years of experience. Medical Science Monitor: International Medical Journal of Experimental and Clinical Research 2013;19:11831187. doi:10.12659/MSM.889687.

[4] Shashi Prakash Mishra, Satyendra Kumar Tiwary, Manjaree Mishra, and Ajay Kumar Khanna, "Phyllodes Tumor of Breast: A Review Article," ISRN Surgery, vol. 2013, Article ID 361469, 10 pages, 2013. doi:10.1155/2013/361469

[5] Primary treatment of cystosarcoma phyllodes of the breast. Chaney AW, Pollack A, McNeese MD, Zagars GK, Pisters PW, Pollock RE, Hunt KK. Cancer. 2000;89(7):1502

[6] Chaney AW, Pollack A, McNeese MD, et al. Primary treatment of cystosarcoma phyllodes of the breast.Cancer. 2000;89(7):1502-11.

[7]Reinfuss M, Mituś J, Duda K, et al. The treatment and prognosis of patients with phyllodes tumor of the breast: an analysis of 170 cases. Cancer. 1996;77(5):910-16.

[8]B. Salvadori, F. Cusumano, R. Del Bo et al., "Surgical treatment of phyllodes tumors of the breast,"Cancer, vol. 63, no. 12, pp. 2532-2536, 1989.

[9] L. Bernstein, D. Deapen, and R. K. Ross, "The descriptive epidemiology of malignant cystosarcoma phyllodes tumors of the breast," Cancer, vol. 71, no. 10, pp. 3020-3024, 1993.

[10] Schnitt SJ, Collins LC. Philadelphia, PA: Wolters Kluwer, Lippincott Williams \& Wilkins; 2009. Biopsy Interpretation of the Breast; pp. 15481.

[11] West TL, Weiland LH, Clagett OT (1971) Cyst osarcoma phyllodes. Ann Intern Med173:520-528.

[12] Mangi AA, Smith BL, Gadd MA, et

al. (1999) Surgical management of phyllodes tumors. Arch Surg 134:487-492.

[13] Spitaleri G, Toesca A, Botteri E, Bottiglieri L, Rotmensz N, Boselli S, Sangalli C, Catania C, Toffalorio F, Noberasco C, Delmonte A, Luini A, Veronesi P, Colleoni M, Viale G, Zurrida S, Goldhirsch A, Veronesi U, De Pas TCrit Rev Oncol Hematol. 2013 Nov; 88(2):427-36.'

[14] M. Reinfuss, J. Mitus, K. Duda, A. Stelmach, J. Rys, and K. Smolak, "The treatment and prognosis of patients with phyllodes tumor of the breast: an analysis of 170 cases," Cancer, vol. 77, pp. 910-916, 1996. 
[15] C. L. Chua, A. Thomas, and B. K. Ng, "Cystosarcoma phyllodes: a review of surgical options," Surgery, vol. 105, no. 2 I, pp. 141-147, 1989

[16] Hopkins ML, McGowan TS, Rawlings G (1994

) Phylloides tumor of the breast: a report of 14 cases. J Surg Oncol 56:108-112.

[17] Chua CL, Thomas A, Ng BK (1989) Cystosarco ma phyllodes: a review of surgical options. Surgery 105:141-147.

[18] Stebbing JF, Nash AG (1995) Diagnosis and management of phyllodes tumour of the breast: experience of 33 cases at a specialist centre. Ann R Coll Surg Engl 77:181-184.

[19] The treatment and prognosis of patients with phyllodes tumor of the breast: an analysis of 170 cases. Reinfuss M, MituśJ, Duda K, Stelmach A, RyśJ, Smolak K. Cancer. 1996;77(5):910

[20] Krishnamurthy S, Ashfaq R, Shin HJ, Sneige N. Distinction of phyllodes tumor from fibroadenoma: A reappraisal of an old problem. Cancer 2000;90:342-9.

[21] Optimising preoperative diagnosis in phyllodes tumour of the breast. Jacklin RK, Ridgway PF, Ziprin P, Healy V, Hadjiminas D, Darzi A. SOJ Clin Pathol. 2006;59(5):454

[22] Needle core biopsy in the diagnosis of phyllodes neoplasm. Dillon MF, Quinn CM, McDermott EW, O'Doherty A, O'Higgins N, Hill AD. Surgery. 2006;140(5):779

[23] Koerner FC. Phyllodes tumor. In: Koerner FC, editor. Diagnostic Problems in Breast
Pathology.Philadelphia, PA: Saunders, Elsevier; 2009. pp. 329-41.

[24] Maier WP, Rosemond GP, Wittenberg P, et al. (1968) Cystosarcoma phyllodes mammae. Oncology 22:145-158.

[25] Mangi AA, Smith BL, Gadd MA, et al. (1999) Surgical management of phyllodes tumors.Arch Surg 134:487-492.

[26] Buchberger W, Strasser K, Helm K, et al. (1991) Phylloides tumor: findings on mammography, sonography and aspiration cytology in 10 cases. Am J Roentol

[27] Blanco AJ, Serrano BV, Romero RR, et al. (1999) Phyllodes tumors of the breast. Eur Radiol 9:356-360.

[28] Niezabitowski A, Lackowska B, Ryś J, et al. Prognostic evaluation of proliferative activity and DNA content in the phyllodes tumor of the breast: immunohistochemical and flow cytometric study of 118 cases.Breast Cancer Res Treat. 2001;65(1):7785.

[29] Moffat CJC, Pinder SE, Dixon AR, et al. (1995) Phyllodes tumour of the breast: a clinicopathological review of the thirty-two cases. Histopathology 27:205-218.

[30] Bader L, Isaacson C (1961) Bilateral malignant cystosarcoma phyllodes. Br J Surg48:519-521.

[31] A prospective, multi-institutional study of adjuvant radiotherapy after resection of malignant phyllodes tumors. Barth RJ Jr, Wells WA, Mitchell SE, Cole BF. Ann Surg Oncol. 2009;16(8):2288. 